\title{
Healthcare Architecture
}

\author{
An Honors Thesis (HONR 499)
}

By

\section{Dana Graunke}

In collaboration with

Kaylee Ross

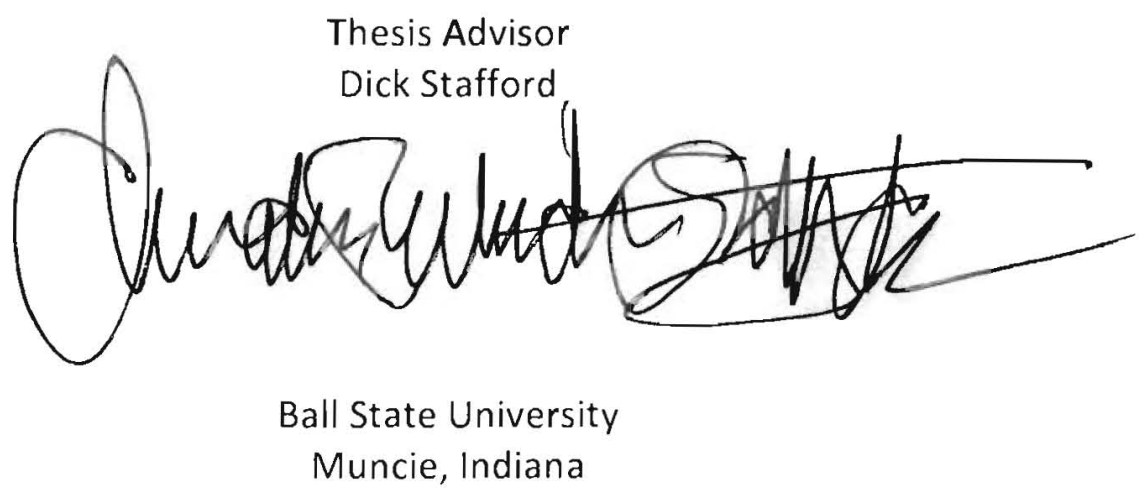

May 2013

Expected Date of Graduation

May 4, 2013 


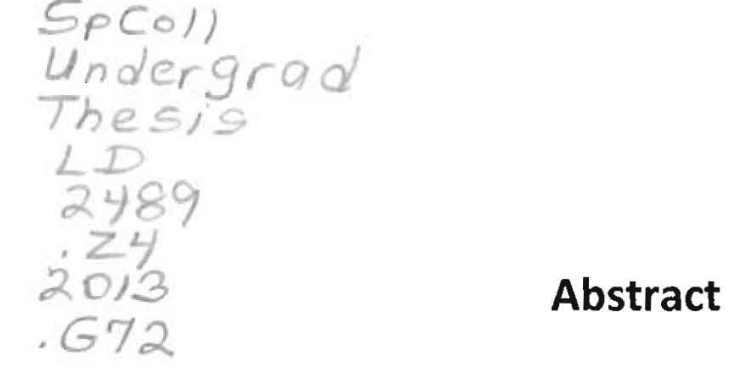

The hospital of St. James in Olympia Fields Illinois was chosen as the site for a hospital renovation and patient distribution and treatment plan. This hospital was redesigned using new and innovative concepts as well understood and tested design theories, focused on creating a healthier comfortable patient focused hospital wing. The old outdated single patient rooms that were previously focused on the quantity of patients instead of the quality of care were restructured to hospice care and creating an environment of healing and positive memories for the patients and their loved ones. Design elements such as frosted glass partitions, a sofa and seating unit with coordinating entertainment and storage unit, provided the comfort of home while increasing the safety and functionality of the rooms to provided the best care and environment. 


\section{Acknowledgements}

I would like to acknowledge all of the support and assistance throughout this project including my thesis partner Kaylee Ross in taking on this challenge with me, along with our thesis mentor Architect Dick Stafford and the additional advice given by Lucas Holwerda, both providing us great insight into not only working architecture but specifically healthcare architecture. I would also like to thank all of the members of Ball State University and the Honors College. Thank you all for this opportunity to share and develop my interest and knowledge in Healthcare Architecture. 


\section{Table of Contents}

\section{Drawings}

North Section Original Floor Plan 1

North Section Original Floor Plan Enlarged 2

North Section Remodel 3

$\begin{array}{ll}\text { Courtyard Remodel } & 4\end{array}$

Waiting Area Remodel 5

Room Plan with Exterior Planter 6

$\begin{array}{ll}\text { Room Plan with Patio } & 7\end{array}$

$\begin{array}{ll}\text { Reflected Ceiling Plan } & 8\end{array}$

Interior Perspective Rendering - View from Patient Bed $\quad 9$

Interior Perspective Rendering - View from Hospital Room Door $\quad 10$

Interior Elevation Rendering - Towards Interior of Building 11

Dual Sided Seating Unit $\quad 12$

$\begin{array}{ll}\text { Entertainment Wall Unit } & 13\end{array}$

Opaque Privacy Wall Swing Diagram $\quad 14$

Window Air Flow Diagrams $\quad 15$

$\begin{array}{ll}\text { Exterior Perspective Rendering } & 16\end{array}$

Essay

$\begin{array}{ll}\text { Site Location and Selection } & 17\end{array}$

$\begin{array}{ll}\text { Precedent Research } & 18\end{array}$

Focus on a Hospice Unit $\quad 19$

Design Process: Creating a Hospice Patient Room 19

$\begin{array}{lr}\text { Conclusion } & 22\end{array}$

$\begin{array}{ll}\text { Work Cited } & 23\end{array}$ 


\section{Healthcare Architecture}

\section{Objective}

Design and redesign of a area within an existing hospital based on the current ideas and knowledge of healthy design along with testing new and innovative ideas. Utilizing current studies and independent research completed by experts in the field and supplemented through our own research. Specifically focus on the layout and positioning of nurses stations, room layout and design and the overall design and locating of spaces within a hospice wing at St. James Olympia Fields in Illinois. The purpose of this project segment is to provided a beginning level of understanding of the details, systems, structures and organization that go into current hospitals and to begin to make connections with the needs and future design models. The final project will be a culmination of architectural drawings, detailing, renderings and project oriented writing.

\section{Goals}

This project focus will give insist into future graduate studies and career opportunities. It is proposed to produce a specific design of high quality with a post undergraduate architectural level of quantity. The projects focus on healthcare is something that has been ever so slightly touched on throughout the years of undergraduate study as a part of the architecture program at Ball State University. The complexity and degree of time needed for see types of projects is very specialized and is to provide great insight and act as a stepping stone to future projects.

\section{Target}

The final project is to be accessible and legible to all however with most architectural projects there are elements that are geared for those that are ever in the study or career path of architecture or those related. Therefore the specific audience is those interested in the studies and designs of hospitals with an architecture or similar background of study. From this those individuals are to be able to understand concepts of design implemented into the hospice wing with greater detail placed on nurses station and hospital room studies and design opportunities. 

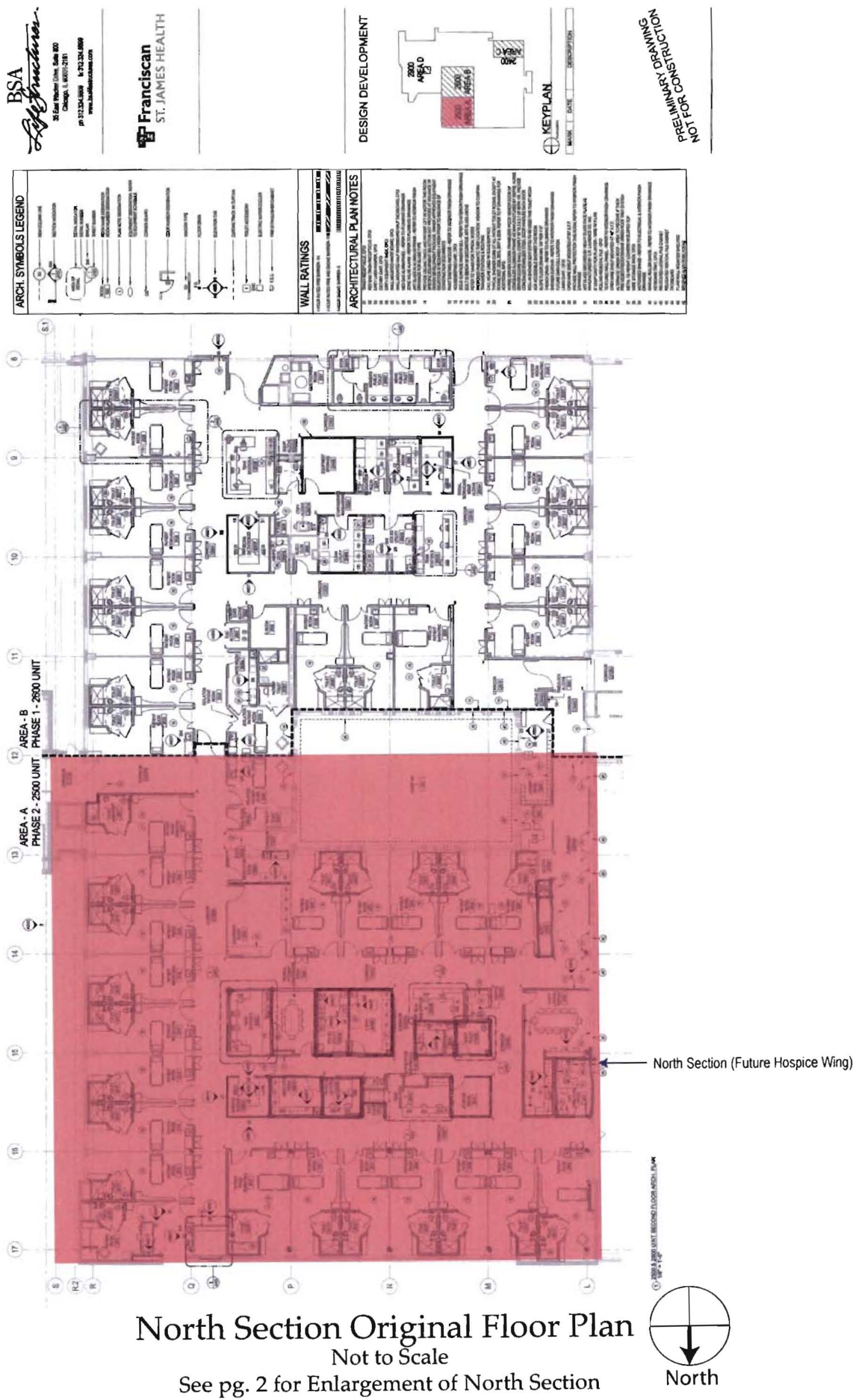

(17)
(16)
15
(14)
(13)
AREA - A 12 AREA - B
PHASE 2 - 2500 UNIT, PHASE 1 - 2
?

\section{s}

(R.2)

(R)

1.

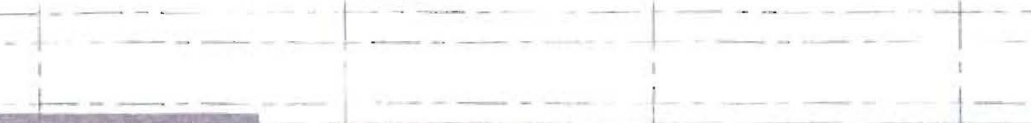

(2)

(2)
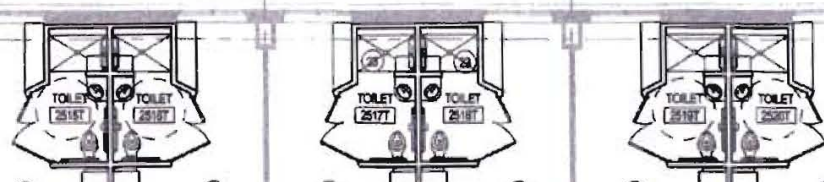

प्र

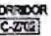
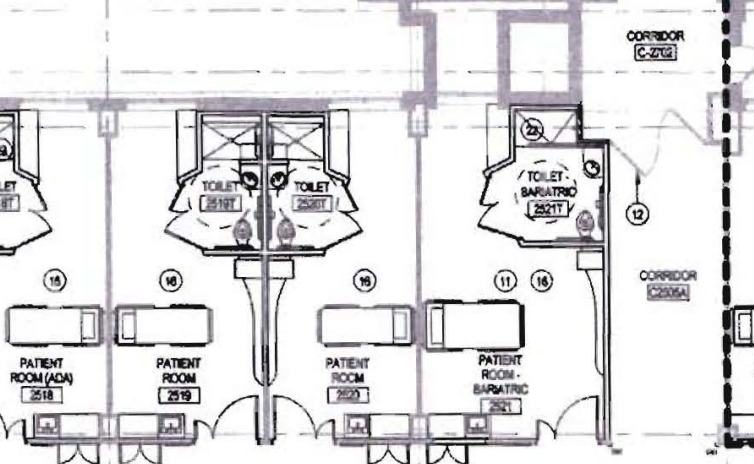

sopors
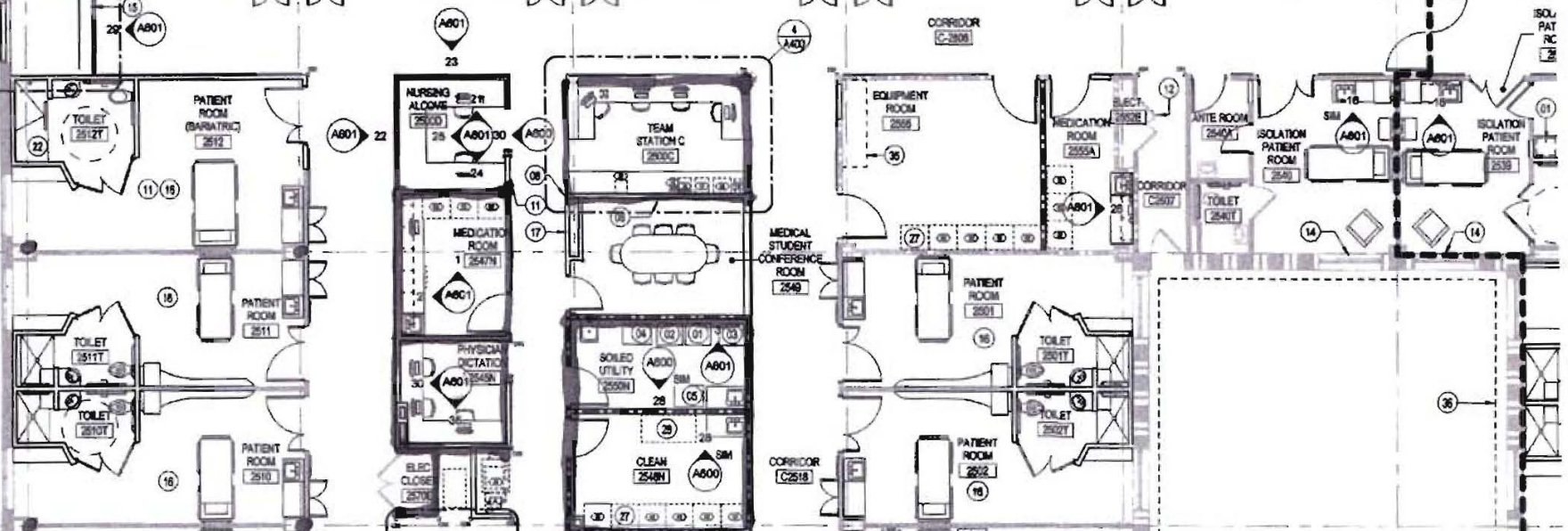

(i.)

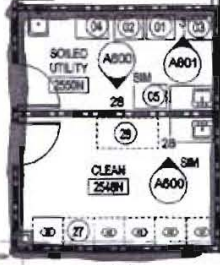

(1)

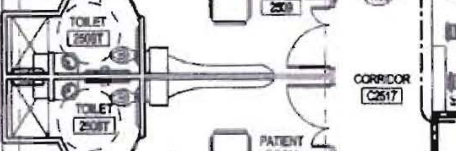
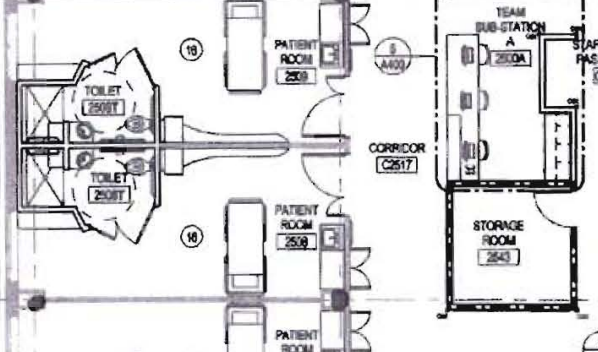

(3)

(1)

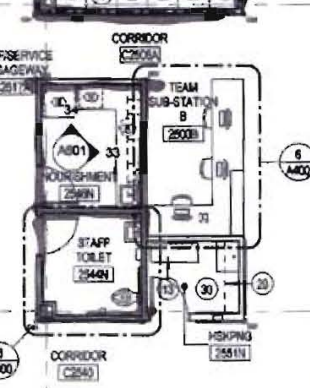

$\rightarrow$ 
1) Manager's Office

2) Mens Public Bathroom

3 ) Womens Public Bathroom

4) Courtyard (enlarged pg. 4)

5) Staff Lounge

6) Patient Rooms

7) Waiting Room (enlarged pg. 5)
8) Stone Surround Fire Place

9) Nurses Station

10) Staff Bathroom

11) Equipment Storage Room

12) Medication Distribution

13) Conference Room

14) Physician Dictation
15) Soiled Utility

16) Clean Utility

17) Electrical Closet

18) Print Cubby

19) Staff Locker Room

20) Nutrition

21) Planters

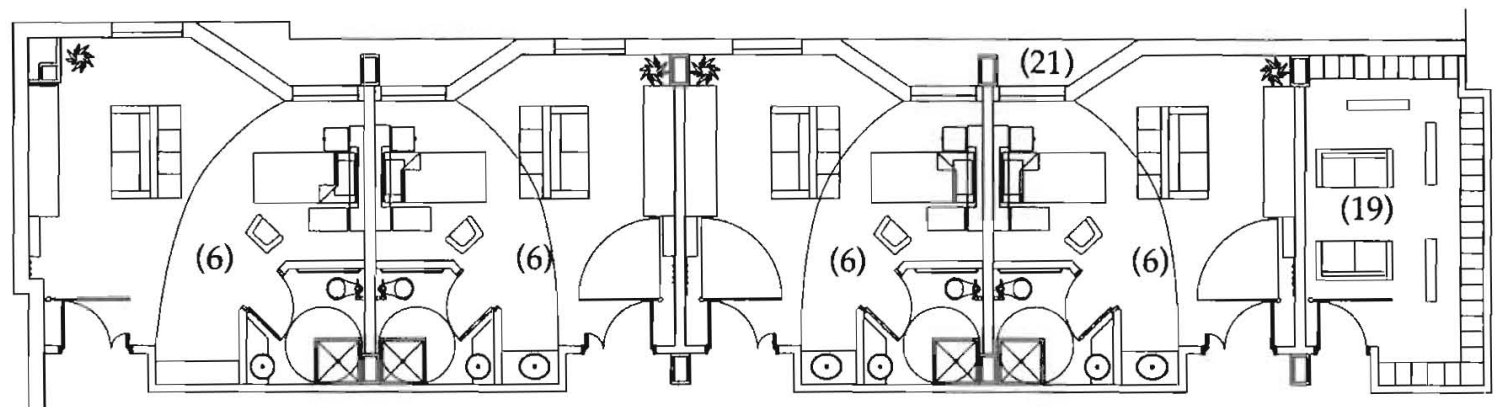

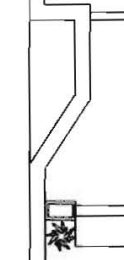

\section{(11)}
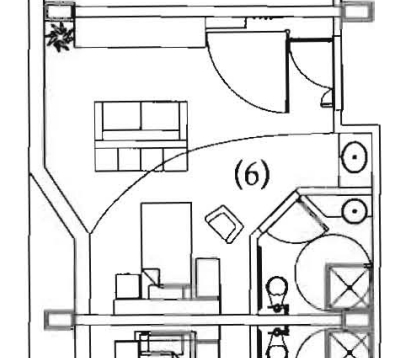

I

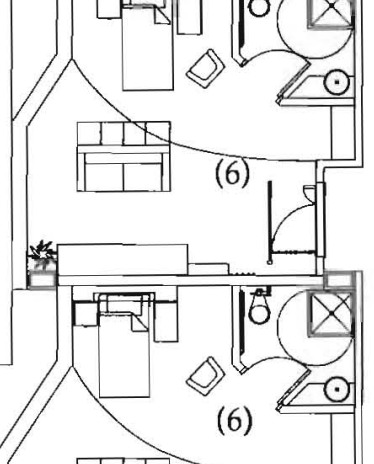

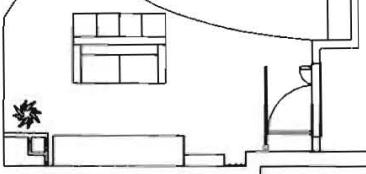
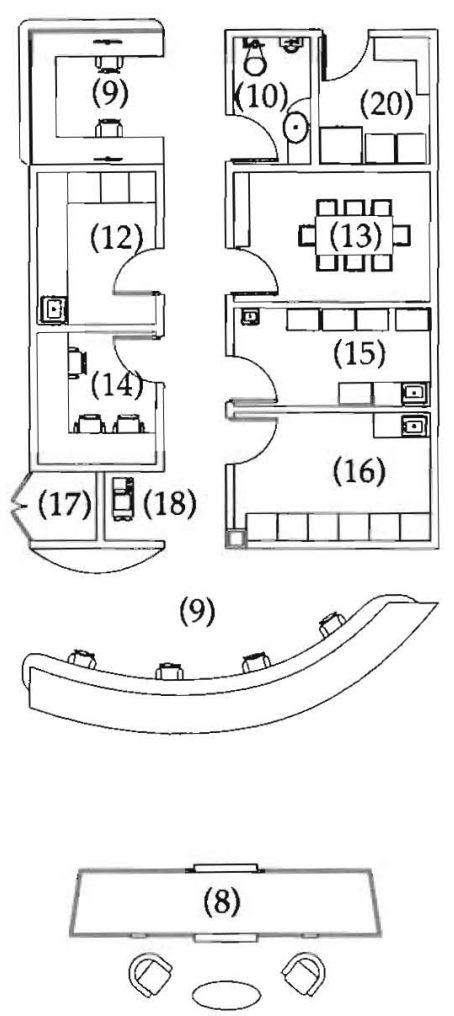

$\square(7)$

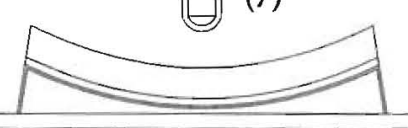

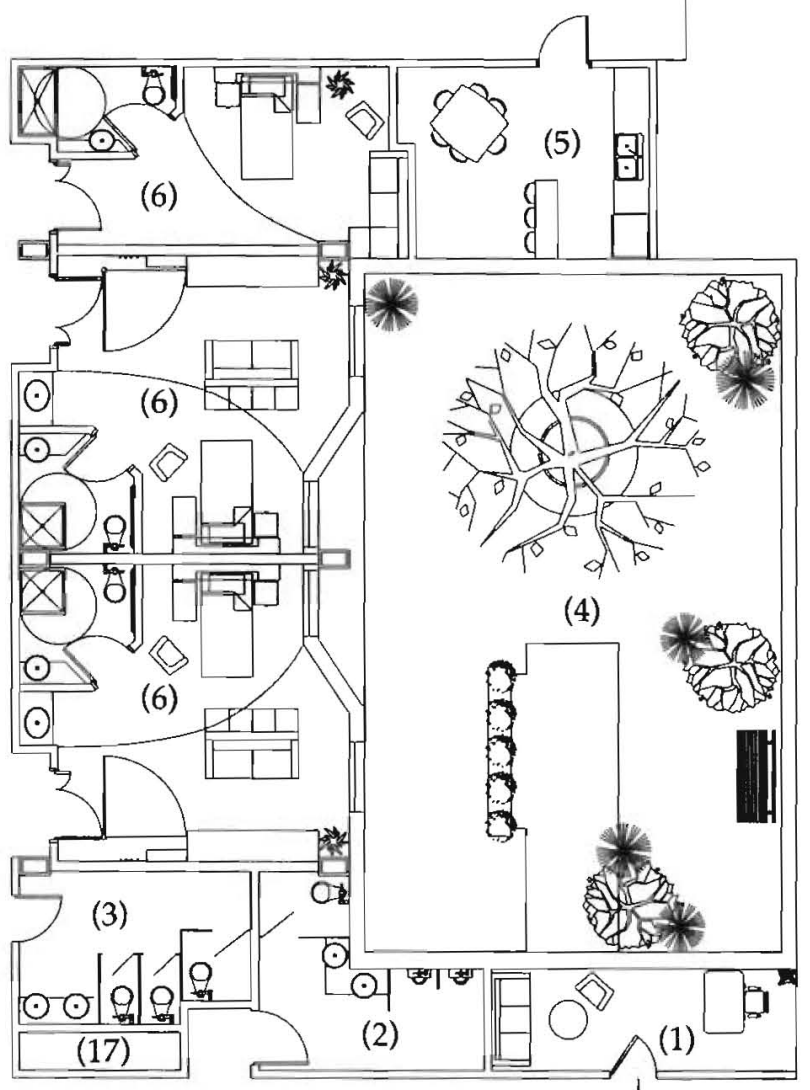

North Section Remodel

Scale $1^{\prime \prime}=10^{\prime}$

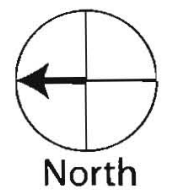




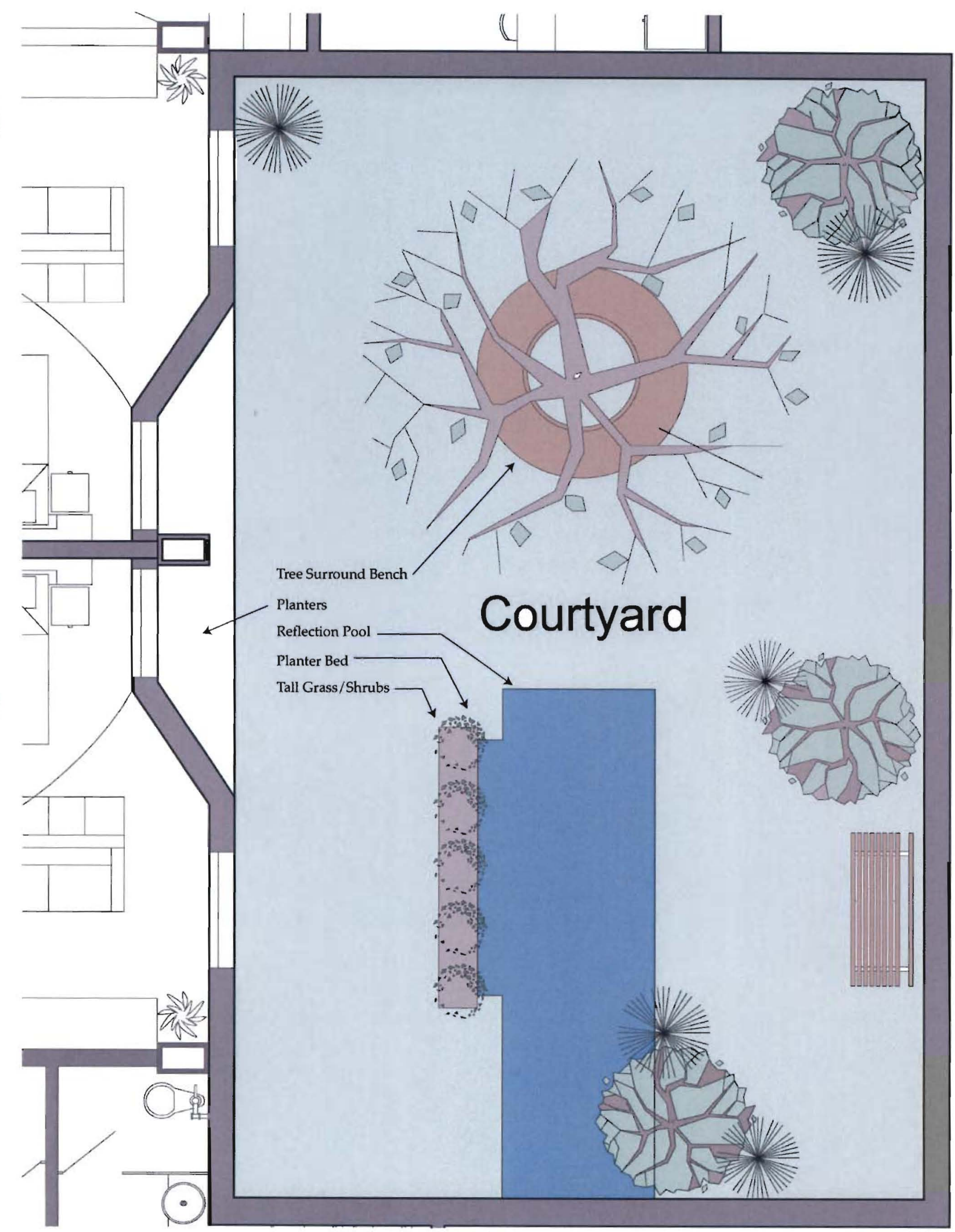

Courtyard Remodel

$$
\text { Scale } 1^{\prime \prime}=5^{\prime}
$$

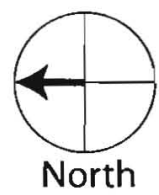




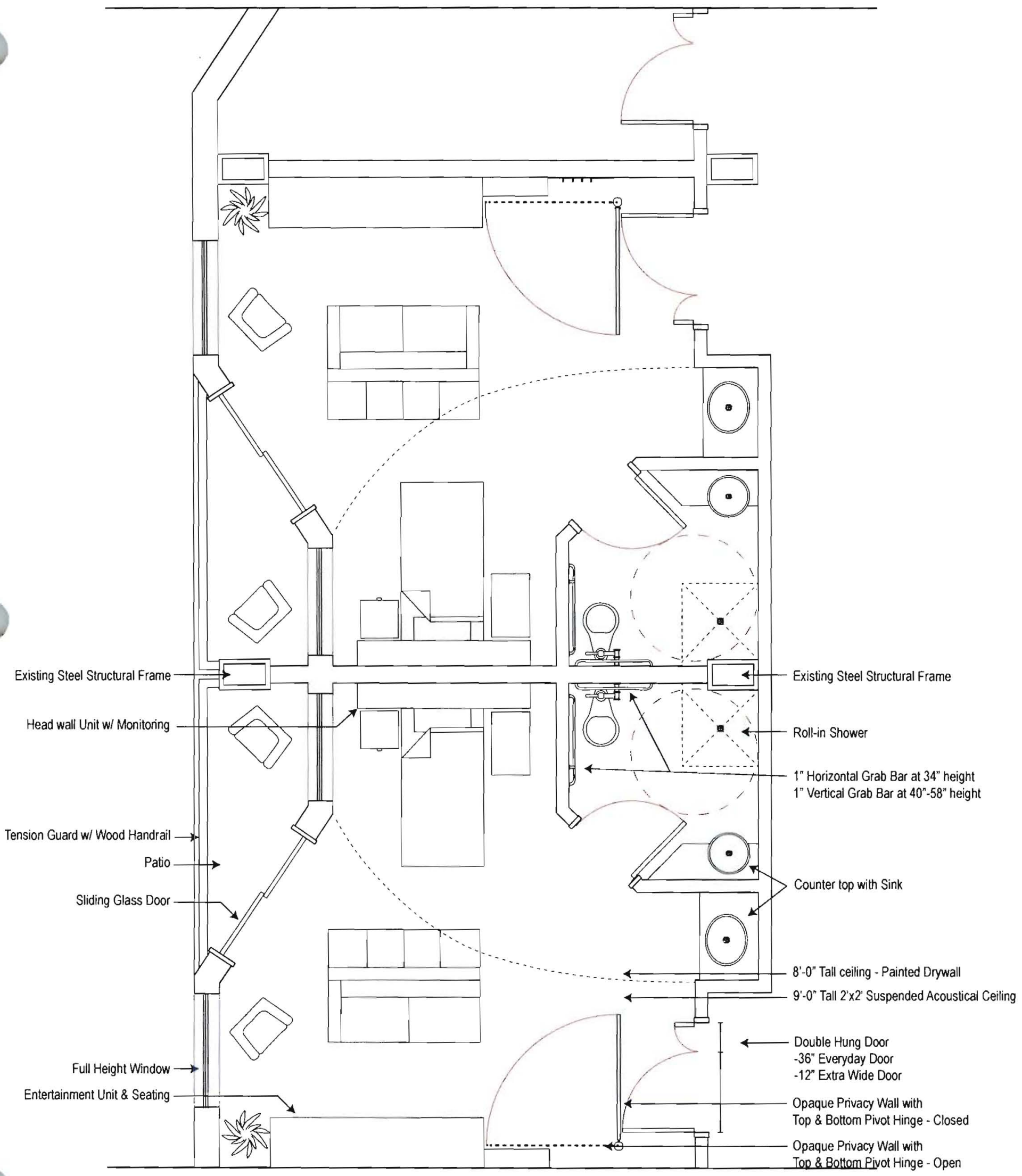

Room Plan with Patio

Scale $1^{\prime \prime}=5^{\prime}$

Variation Two 
1) Down light - LED

2) Multifunction Light - 24" x 48" Ceiling Mounted

3 ) Head wall Diffuse Light - Wall Mounted Linear Fluorescent

4) Wall Sconce - Decorative Diffused Light

5) Vanity Mirror - Wall Mounted Above Sink

6) Step Light - Recessed LED

7) 1/4" Expansion Joint

8) 8'-0" Tall Ceiling - Painted Drywall

9) $9^{\prime}-0^{\prime \prime}$ Tall Ceiling - 2'x2' Suspended Acoustical Ceiling
1)

2)

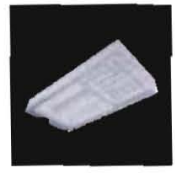

3)

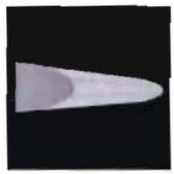

5)

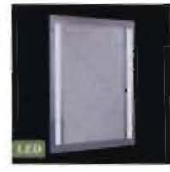

6)

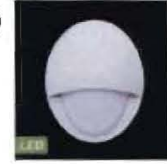

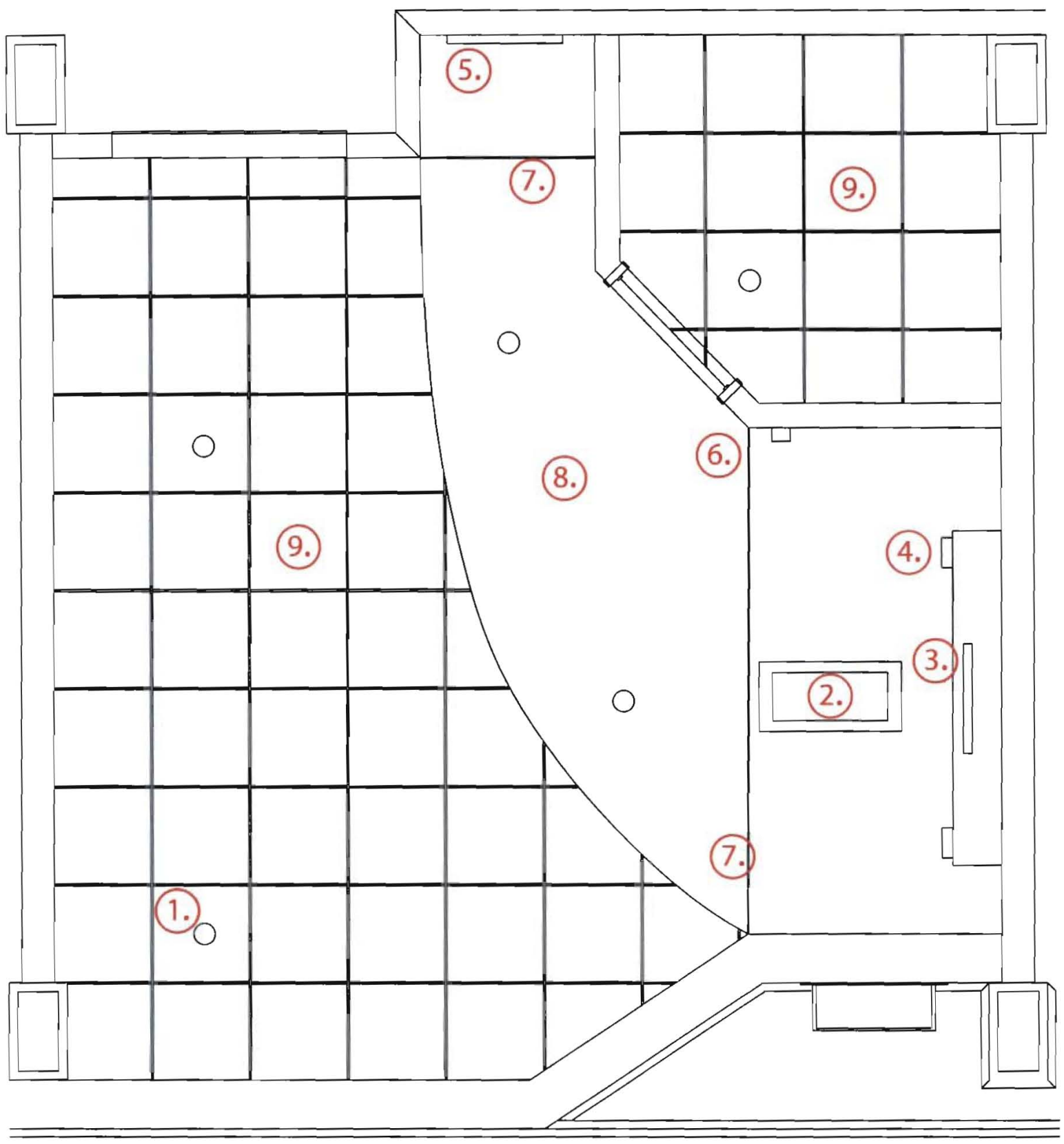



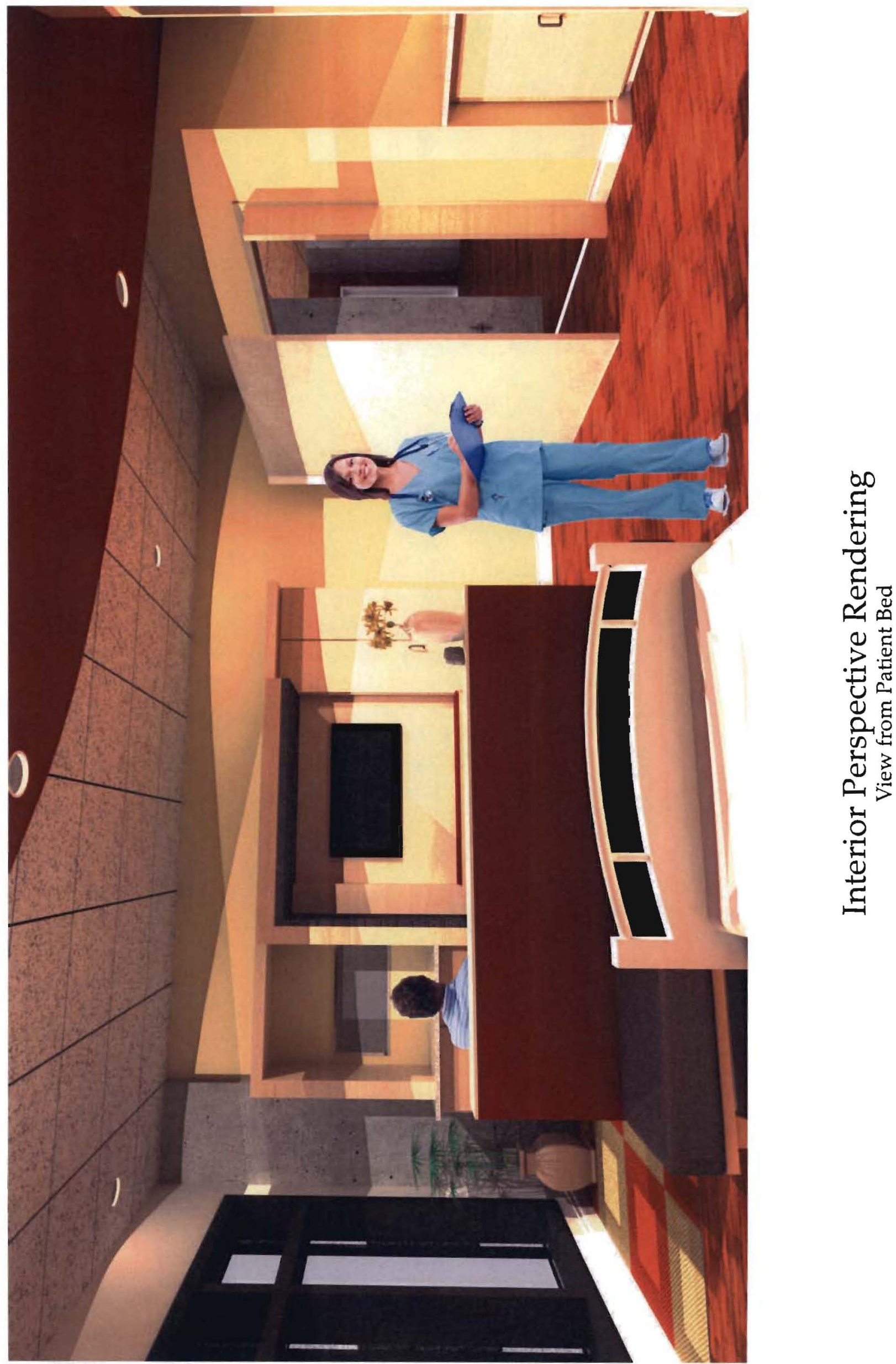

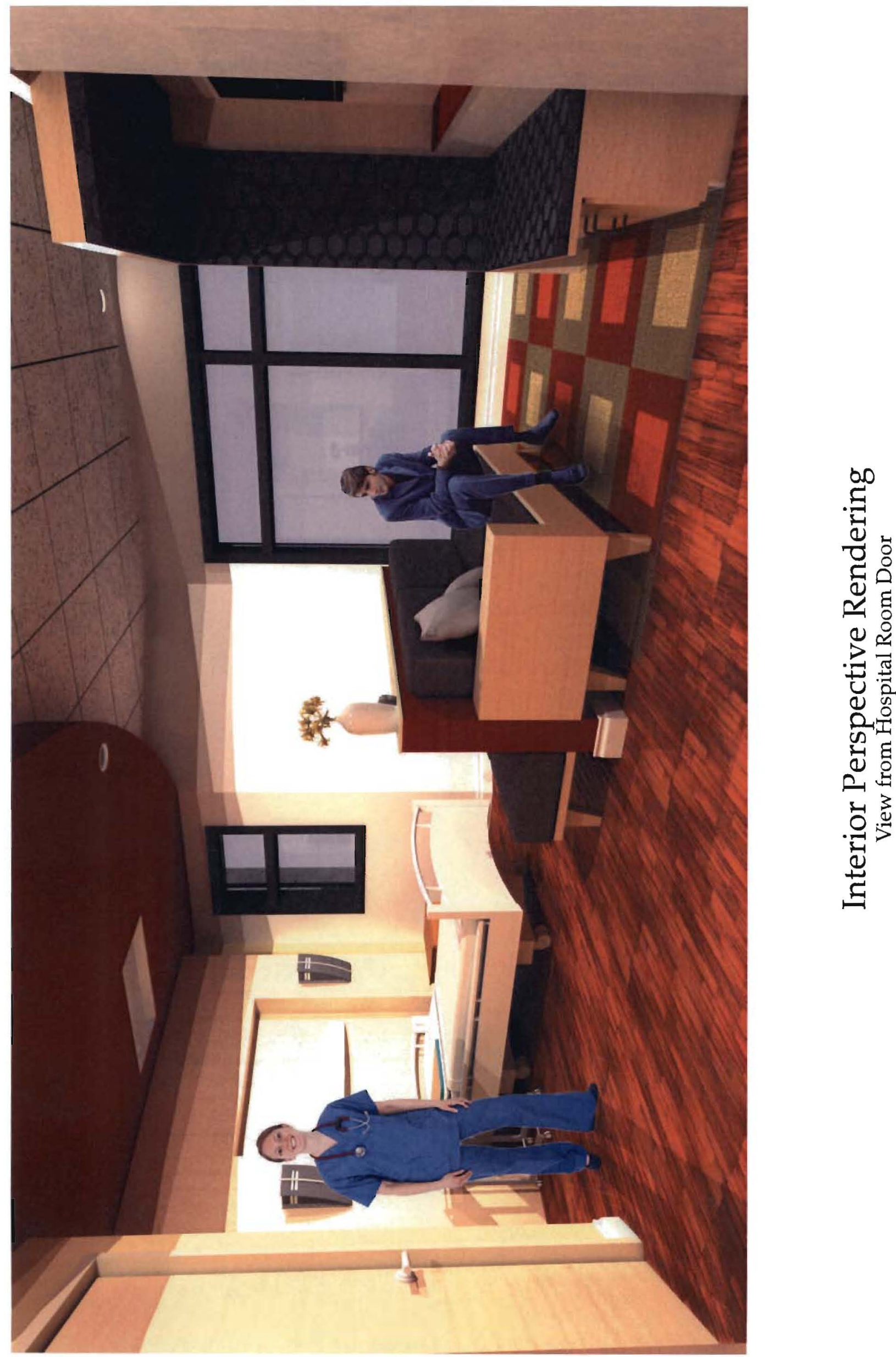

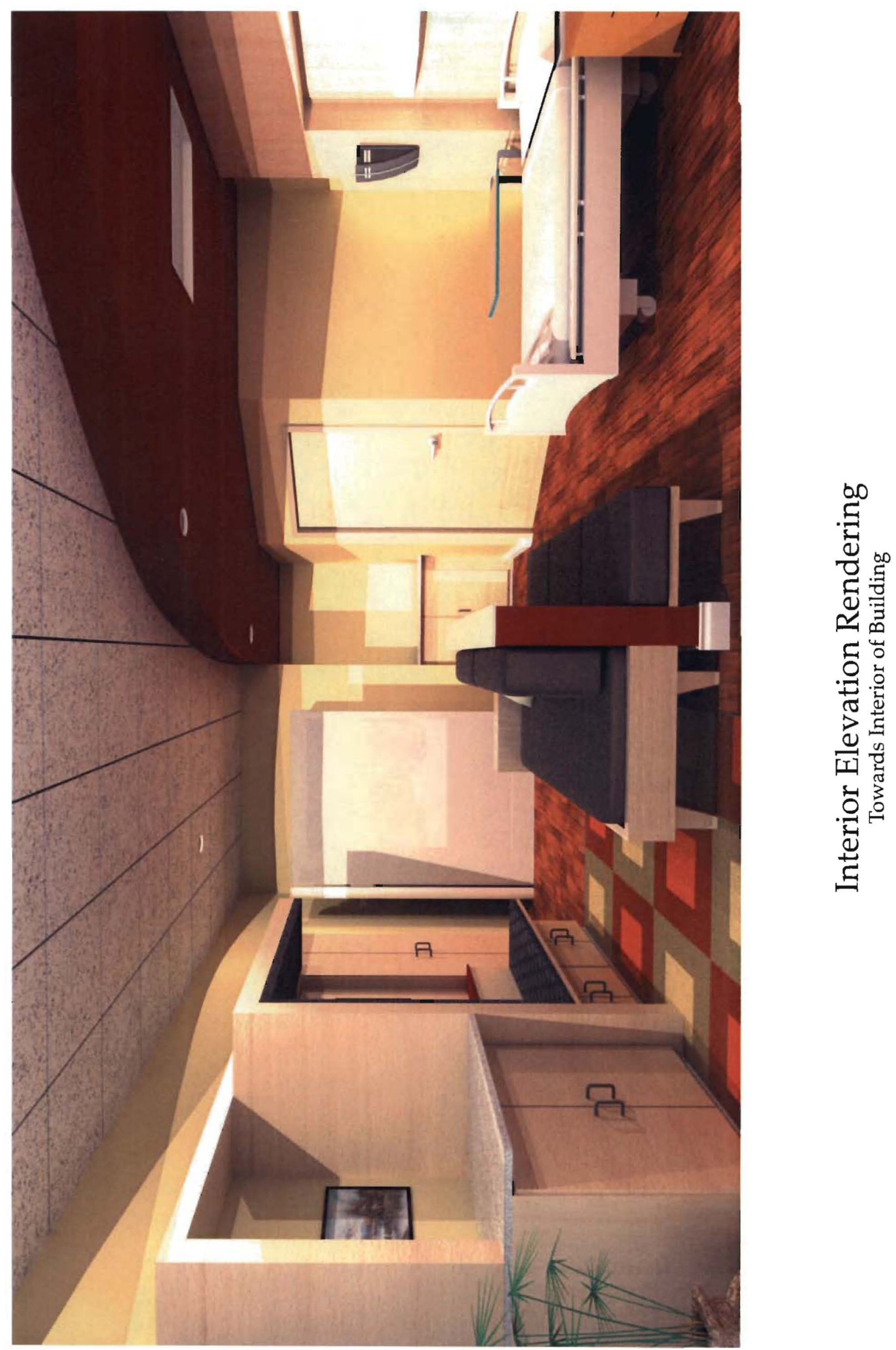

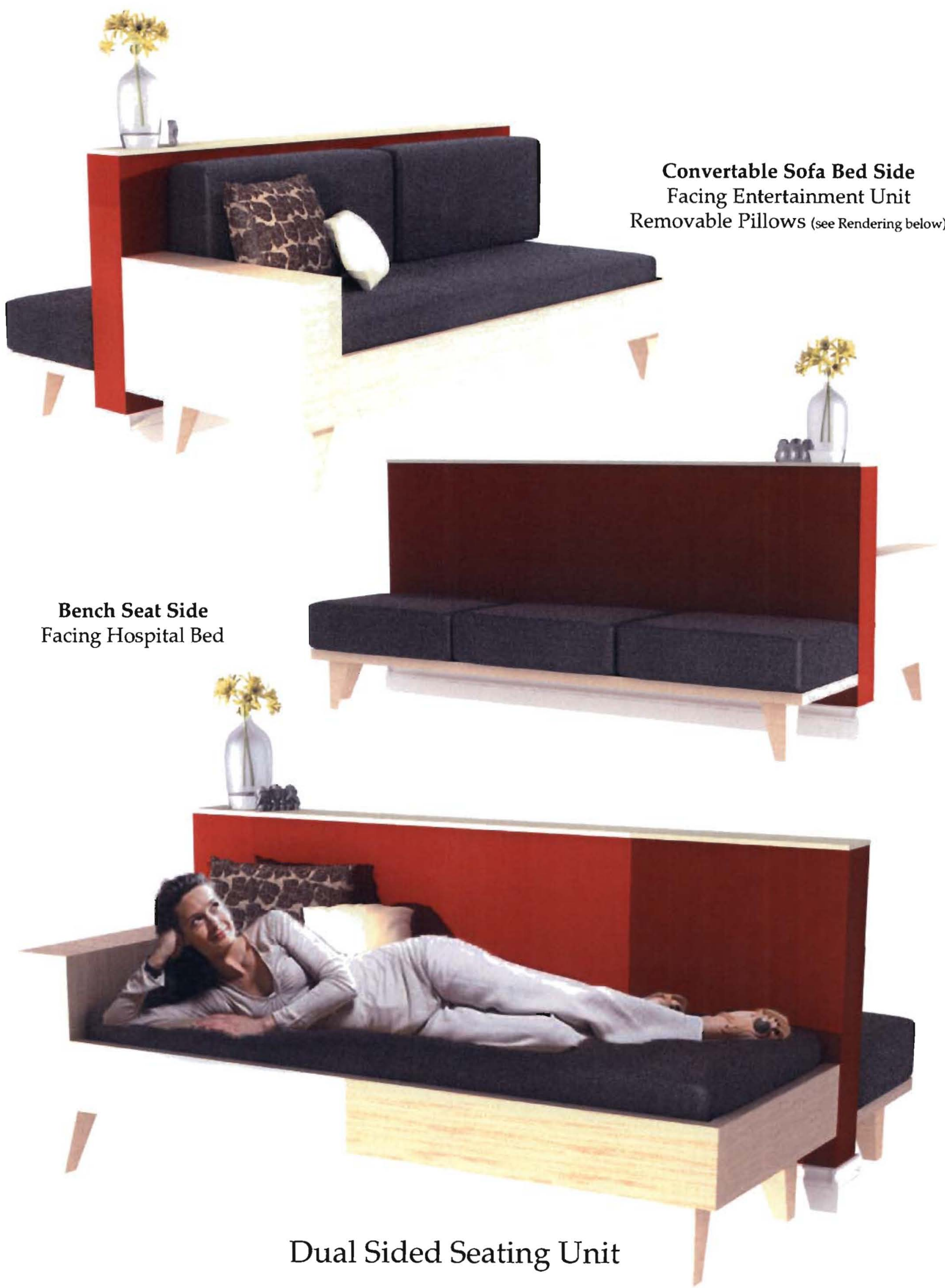

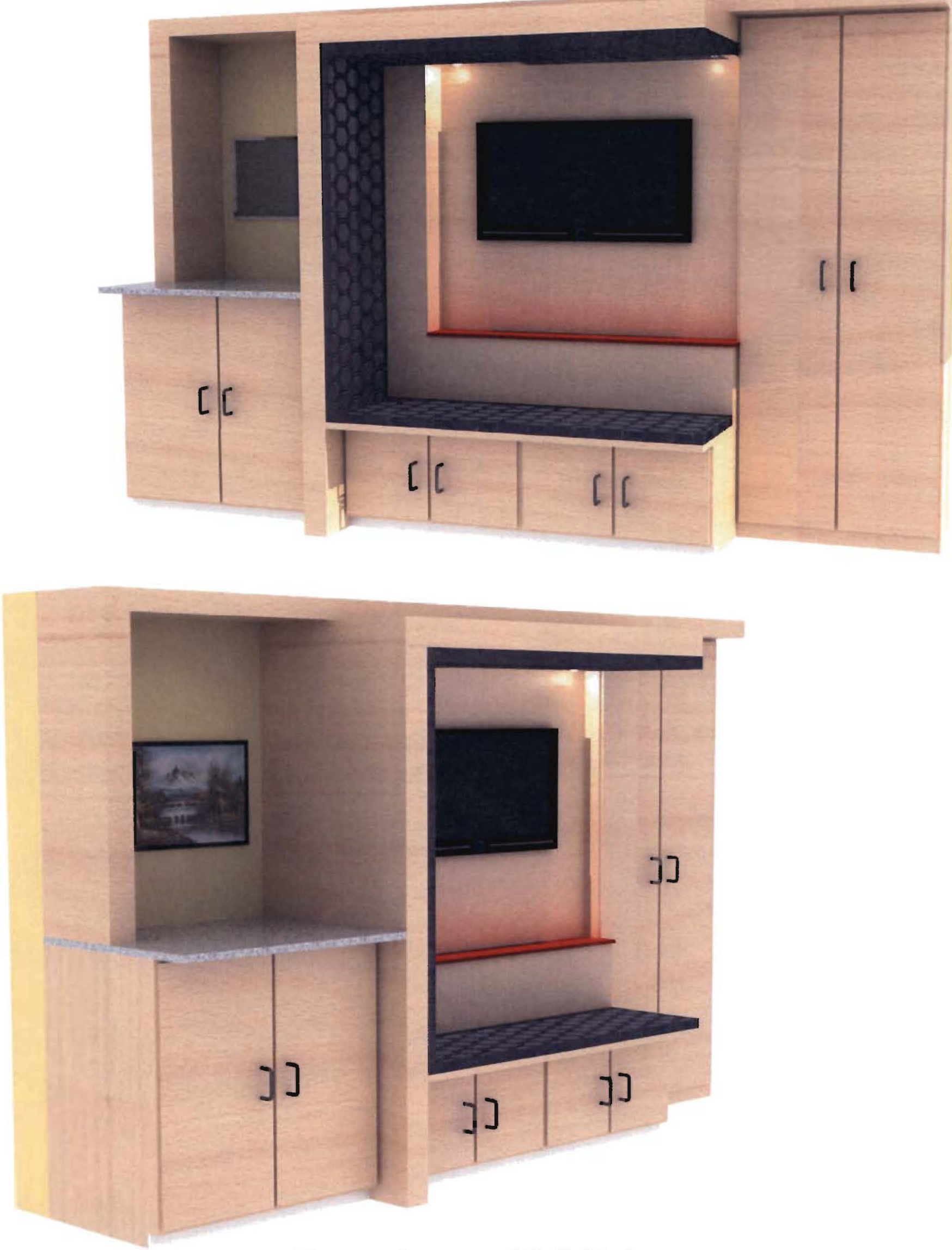

Entertainment Wall Unit

Built in Bench Seat and Storage 


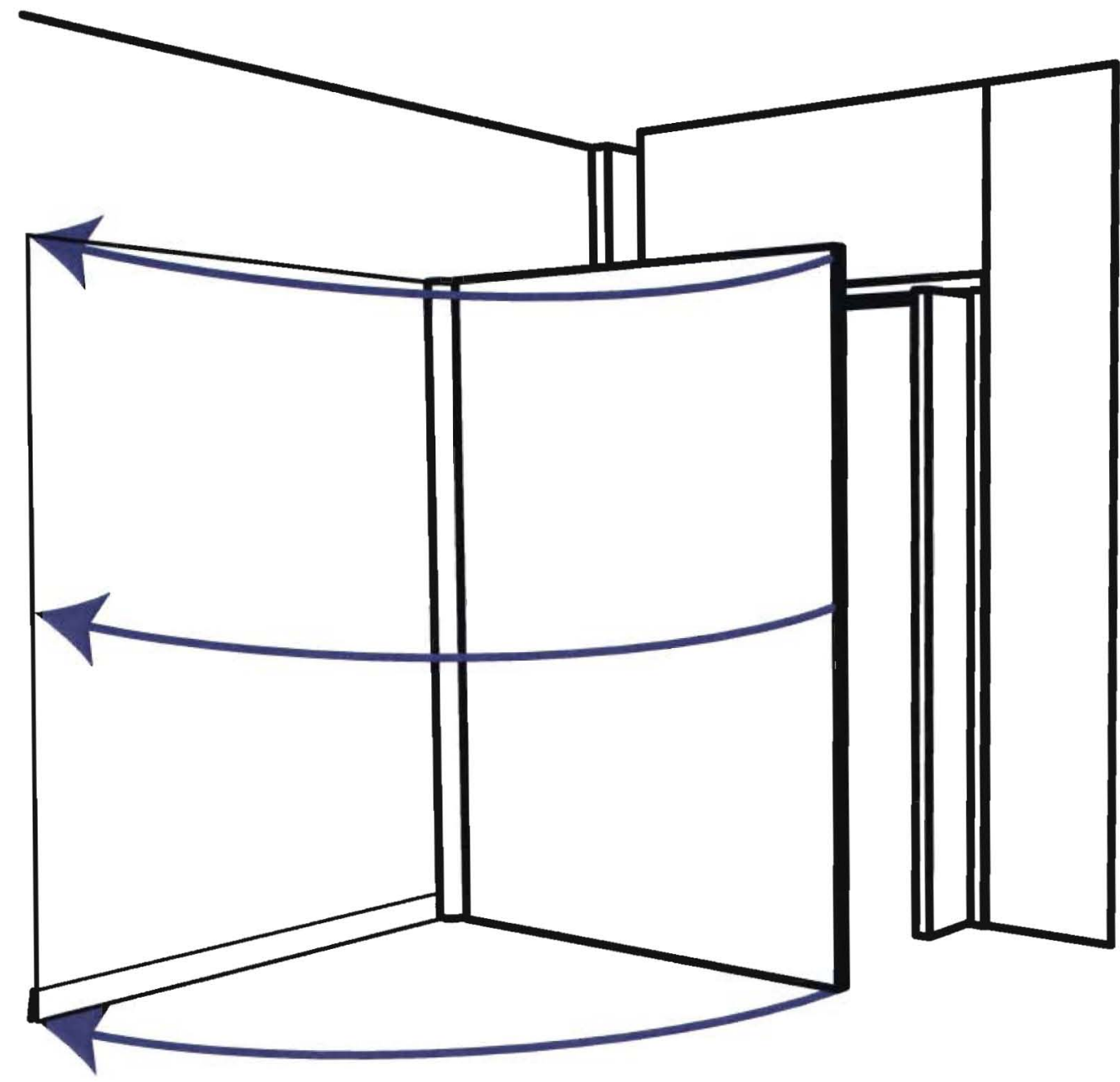

Opaque Privacy Wall Swing Diagram

Top \& Bottom Pivot Hinge 

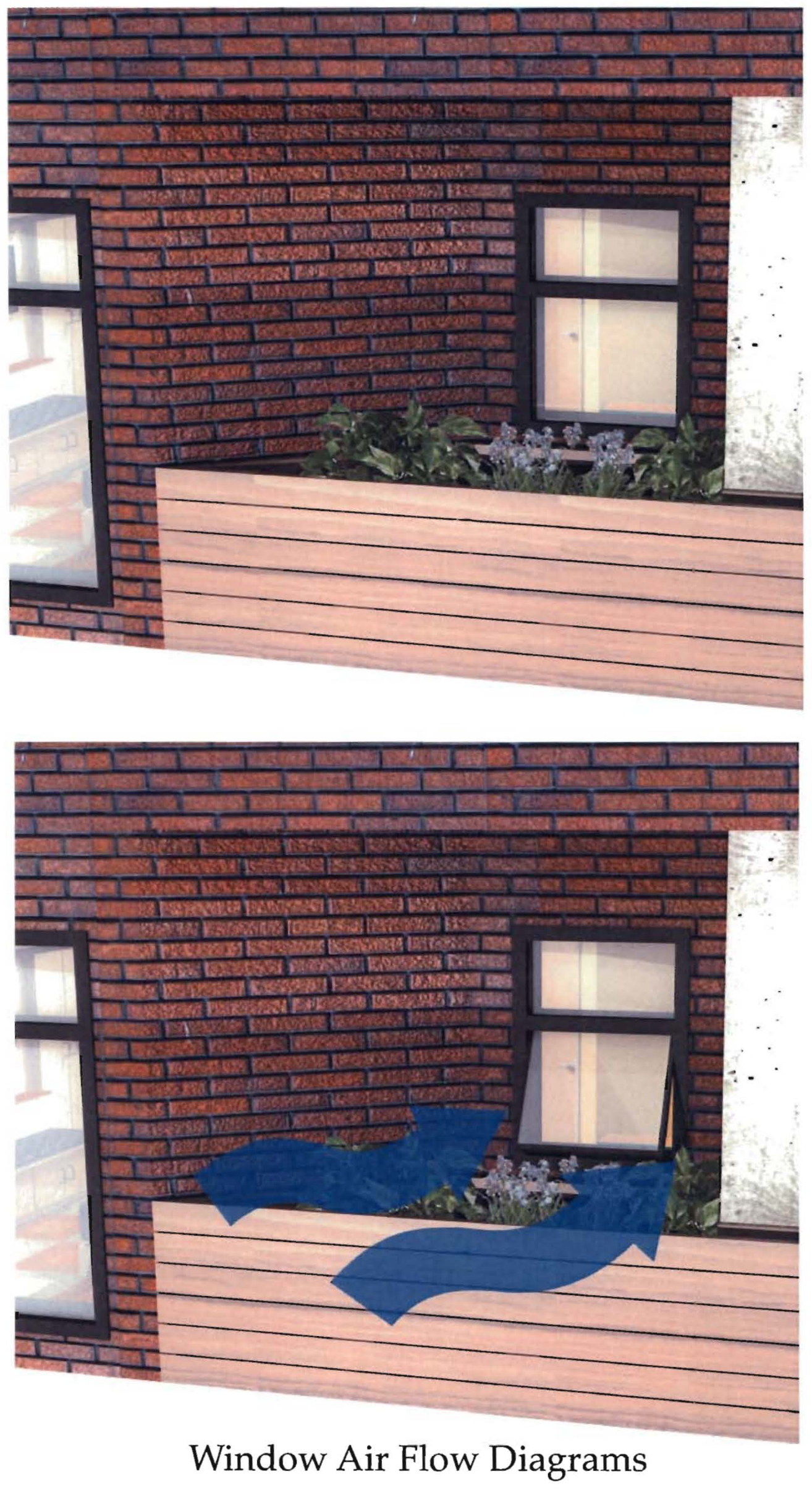


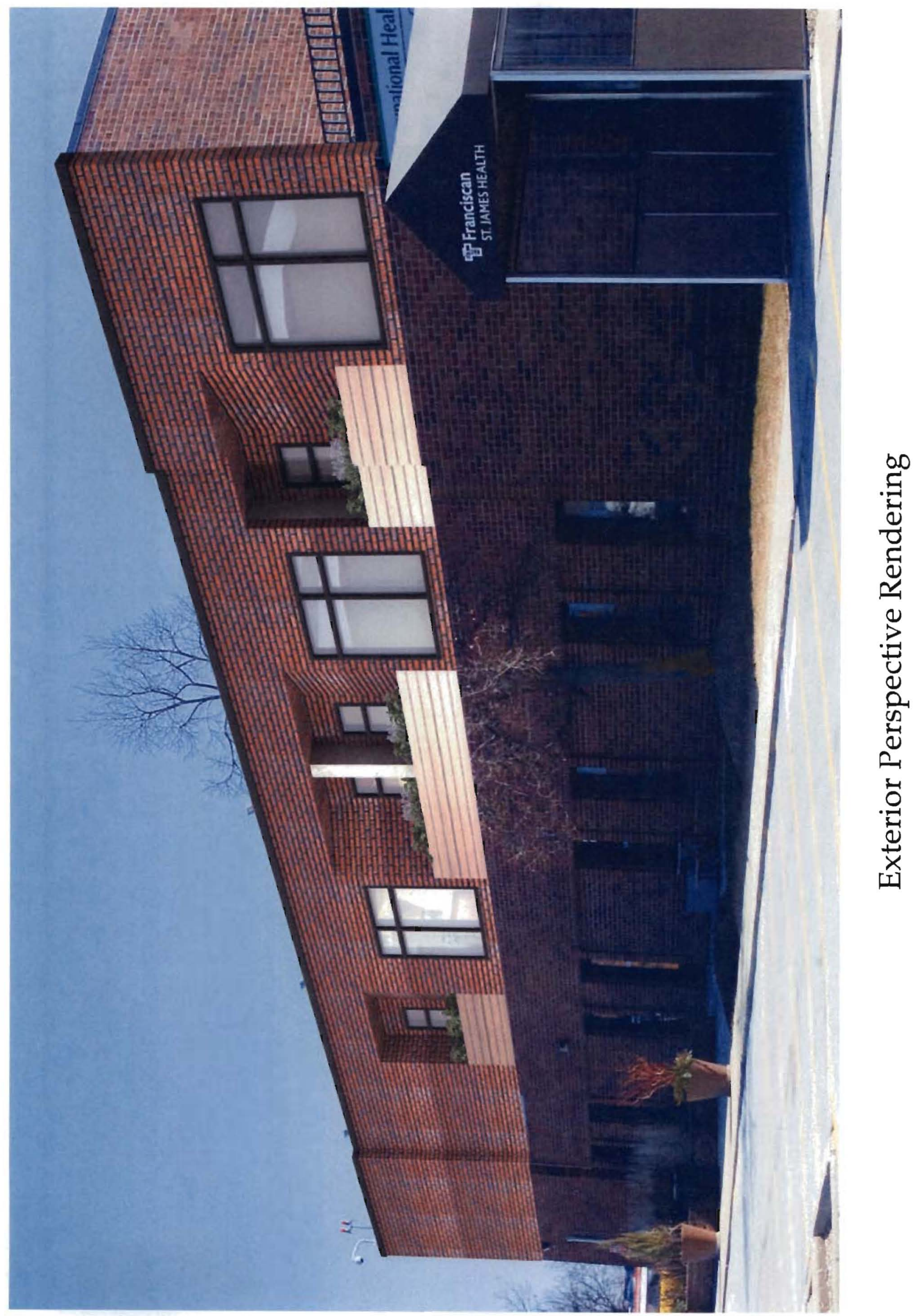




\section{SITE LOCATION AND SELECTION}

In order to experience what it is realistically like to design a hospital wing, we decided to choose an existing hospital for which we could create a renovation proposal. The hospital that we chose is St. James Hospital in Olympia Fields, Illinois. St. James is a hospital that is owned by the Franciscan Alliance, Inc. which owns numerous hospitals throughout Indiana and some in Illinois. St. James in Olympia Fields is a major hospital in the southern suburbs of Chicago, which is a highly competitive area for healthcare. There are many hospitals in the area and St. James needs to compete to attract patients to their facility. The main way that St. James has been attracting patients is through a series of phased renovations to their outdated facility. Healthcare is an ever changing profession that is constantly evolving with new technologies. An outdated facility can extremely hinder an organization. So in order to keep up with the times and remain a competitive organization St. James needed some updates.

The first renovation the hospital underwent was completed in 2003 by BSA Life Structures. The new addition consisted of a new main entrance, emergency room, testing facilities, as well as two

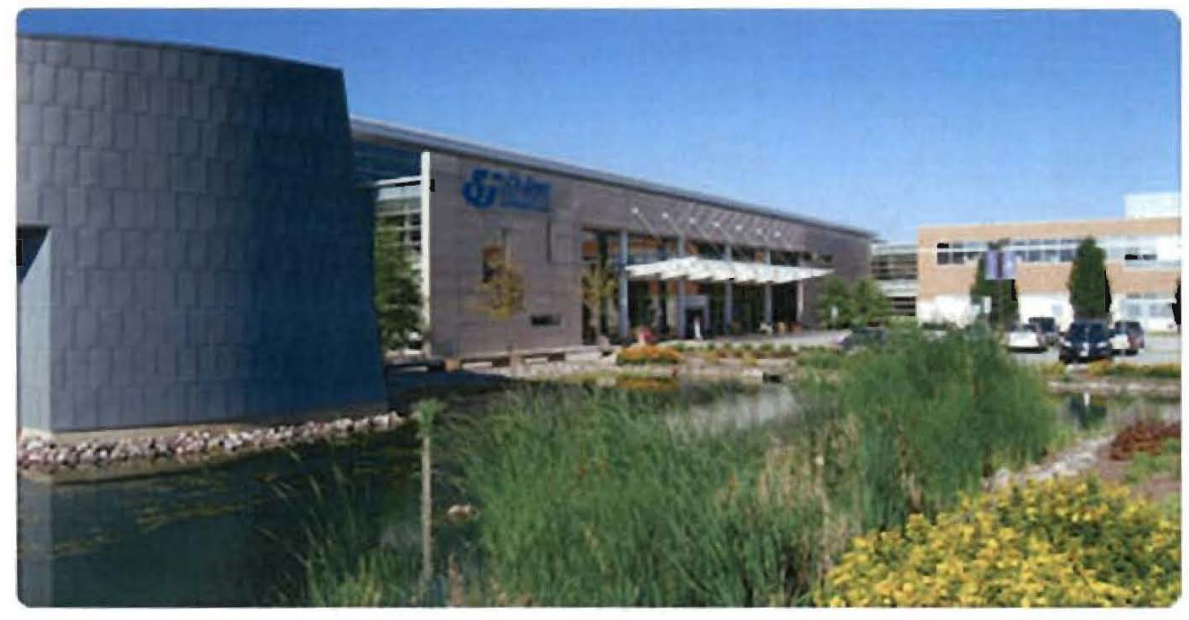
cardiovascular inpatient units. This remodel gave a new face to St. James, drastically boosting its image. Since this renovation proved effective, the organization

made the decision to continue the updates by renovating an older inpatient unit within the hospital.

The construction for this phase is currently taking place. This updated unit will increase the capacity of the hospital and the quality of stay with additional single rooms. 
Since St. James is actively attempting to keep up with the times through this series of renovations, we thought that this granted an excellent realistic opportunity for a design proposal that could become a future goal for the hospital. With St. James seeking to eventually make improvements to its entire facility, we decided to take one of the existing older units and redesign it in appropriation with modern day healthcare. Our general floor plan acts as a proposal for a phase of renovations that the hospital could essentially pursue in the future. This floor plan is our proposal for a hospice unit at the St. James Olympia Fields campus, something which the hospital currently does not have.

\section{PRECEDENT RESEARCH}

Through the development of the renovation for St. James Hospital in Olympia Fields, we looked at a variety of precedents to get an idea for feasible design in a healthcare unit. The precedent research we did gave us an understanding of what could be done in the space that we had to design in. One example of a spacious hospital room was from the book Evidence-Based Healthcare Design. This room made excellent connections to the exterior with its large windows and incorporation of nature. The cover of the book features a hospital room with many of the same features we utilized in different manners within our own room design. The large amount of natural lighting and deck space was incorporated into one version of our design layout (see pg. 7). Another valuable precedent for our waiting area was out of October 2012's edition of Healthcare Design Magazine. This created the idea of utilizing comforting aspects such as a fireplace within the waiting area and decreasing the minimizing the scale, that is typically associated with hospitals, into something that evoked the emotion of comfort. It is now a space where one would be able to sit while waiting to see their loved ones. All of the precedents played a role in the design and shaped our healthcare design ideas. 


\section{FOCUS ON A HOSPICE UNIT}

Dramatically different than any other part and function of a hospital, the hospice wing and care unit focus primarily on patient comfort and care. Hospice is the only place in the hospital where the end result is ultimately known: death. With that, the original design of St. James Hospital in Olympia Fields is ill prepared to accommodate the sort of focus on care that a hospice unite requires. By redesigning the unit specifically as a hospice wing, we were able to take a deeper look at the patient comfort and family accommodations that are desired in the room and public spaces. In our design, we sought out to provide the patients with a homey and private feel with the same safety precautions and technology that typical hospitals have in place. This combination produces a high quality design, providing the best for the minimal time that these patients have remaining. Minor touches of color and detailing of furniture, artwork and elements found in homes such as fireplaces and carpeting in the public area create that high quality feel with a more warming comfortable experience for all.

\section{DESIGN PROCESS: CREATING A HOSPICE PATIENT ROOM}

In designing the new unit, we first had to analyze the existing conditions of the hospital to recognize the structure, which became the parameter in which we could design. The existing hospital plan had 21 single patient rooms. Though this is fine in a normal hospital unit to accommodate high census, with a hospice wing, we decided it was important to provide as much comfort as possible rather than providing as many beds as possible. In order to improve the size of the patient rooms, we doubled the dimensions of the existing rooms by following the concrete structural grid, making the new room dimensions 21'x19'. Enlarging the rooms was done strategically for a number of different reasons. 
When patients are in a hospice room, of which the sole purpose is to provide comfort near the end of one's life, they want to feel as though they are at home and not in a sterile hospital room. Opening up the room allowed us to provide more amenities to maximize the patients comfort. Also, most of the time when a patient is in a hospice wing, family and friends are constantly in and out visiting. This new room design allows for family feel more comfortable while they are visiting.

Throughout our research of hospital design and patient comfort, an emphasis on nature was a predominant theme. Nature plays a huge role in health care design. Nature in and of itself has significant physical and psychological health benefits. It reduces stress, provides a feeling of comfort, and can actually promote the healing process. Because of the benefits that nature has on healing, we wanted to incorporate natural elements wherever possible. We decided to cut into the exterior building envelope in order to create a ledge that could sustain a planter bed outside the windows of each patient room. Above each planter bed is a operate window that opens out allowing fresh air to come into the room. This allows the patient to feel as though they are outside while they are in their hospital bed. With the circumstances surrounding a hospice patient is can be very special and beneficial to be able to make that connection with nature.

A specific element of this hospice patient room that we felt necessary to incorporate was a furniture design that provides seating for visitors as well as overnight accommodations when necessary. We made the decision to place the furniture design in the center of the room in order to distinguish the patient's area from the family and visitor's area. A $3 \mathrm{ft}$. half wall comes up, off of which bench seating is attached on the patient's side and a couch/bed is attached on the visitor's side. The bench seating on the patient side allows visitors to sit and converse with the patient, while the couch on the visitor's side lets the visitors sit and pass time more comfortably. At night if a family member wishes to stay with the patient, the cushions can be taken off the back of the couch, converting it into a bed. This bed can 
become an extraordinary thing to have when a family member wishes to stay with a patient near the end of their life. We believe that a hospice room needs a piece of furniture that is multifunctional such as this to accommodate the needs the patient and their visitors have.

Another important furniture design that we decided to add to the room was a storage unit. The importance of storage and counter space are highly underestimated in a hospital room setting. Patients need a place to put all of their person belongings. Similarly nurses and physicians utilize counter space when performing procedures. This unit provides large cabinets for coats and cloths, as well as small cabinets for personal items. This storage unit also incorporates additional counter space for the nurses and physicians to use. The television is mounted on this storage unit, which becomes the focal point of the design. We thought it important to put the television on the visitor's side of the room as to maximize their comfort. However, the half wall also allows the patient to watch television. The storage design also integrates a padded bench for additional seating. This multifunctional unit is very important in giving the patients what is needed to feel more at home in a setting that is anything but.

In the design of this patient room, we really strove to be as innovative as possible to think of things we had not seen before that could positively change the way we see hospital rooms. A unique way in which we chose to respond to this challenge was to include a large translucent plexi-glass swinging door in the room that acts as a privacy feature. This swinging translucent door ultimately replaces a curtain in the patient room. When the translucent panel is open, anyone passing by can see right into the room, however if the patient or the family of the patient desires more privacy, they simply swing the translucent panel to cover the open door. This allows for some privacy while not being shut out to the outside completely. This feature adds a character to the room design while also serving a necessary function. In this sense it is both unique and practical. 


\section{CONCLUSION}

Through the challenge of designing a hospice patient room, we gained a unique perspective on a particular area in architecture that is largely focused on the user and the user's needs. Coming into this project, we wanted to get a better understanding of how to design for the user as opposed to in response of a site. Doing so required more of a psychological analysis of the state of mind a patient is in when they are in a hospital room. Once we understood that fragile state of mind, we were able to begin responding to those needs through our design. In most cases, we found ourselves making design decisions responding to the emotions that we believed the patient or their visitors would have. By changing the way in which we made decisions to be more conscious of the user, our goal in this thesis project was intimately met. Beginning this project, we wanted to understand what it takes to design a hospital room, which we learned requires an understanding of how the ins and outs of a hospital are run on a day-to-day basis. With this understanding, we were able to design a room and a unit that would not hinder the natural flow that a hospital has. In the end, we were able to design a hospice wing that is patient oriented, which is what we sought out to do. This phased proposal fits well into St. James' advancements towards a better healthcare experience. Since we were able to take an existing project and make it our own, our proposal is one that St. James could integrate in the future. Being conscious of the users of a space during the design process has made us better overall designers. Healthcare is a unique form of design, but by focusing on the patient's experience, we feel as though we have designed a room that can better their overall stay and provides them with as much comfort as possible in a difficult time. 


\section{WORK CITED}

Cama, Rosalyn. Evidence-based Healthcare Design. Hoboken, NJ: John Wiley \& Sons, 2009. Print.

"Healthcare Design Magazine: Architecture and Interior Design Trends for Healthcare

Facilities." Healthcare Design Magazine: Architecture and Interior Design Trends for Healthcare Facilities. Vendome Group, n.d. Web. 23 March 2013.

<http://www.healthcaredesignmagazine.com/>.

Marberry, Sara O. Improving Healthcare with Better Building Design. Chicago, IL: Health Administration, 2006. Print.

Winkel, Steven R., David S. Collins, and Steven P. Juroszek. Building Codes Illustrated for Healthcare Facilities: A Guide to Understanding the 2006 International Building Code for Healthcare Facilities. Hoboken, NJ: Wiley, 2007. Print. 